\title{
Nacelle power curve measurement with spinner anemometer and uncertainty evaluation
}

\author{
Giorgio Demurtas, Troels Friis Pedersen, and Rozenn Wagner \\ DTU Wind Energy, Frederiksborgvej 399, 4000 Roskilde, Denmark \\ Correspondence to: Giorgio Demurtas (giorgio@ingdemurtas.it)
}

Received: 5 August 2016 - Discussion started: 2 September 2016

Accepted: 6 January 2017 - Published: 2 March 2017

\begin{abstract}
The objective of this investigation was to verify the feasibility of using the spinner anemometer calibration and nacelle transfer function determined on one reference wind turbine, in order to assess the power performance of a second identical turbine. An experiment was set up with a met mast in a position suitable to measure the power curve of the two wind turbines, both equipped with a spinner anemometer. An IEC 6140012-1-compliant power curve was then measured for both wind turbines using the met mast. The NTF (nacelle transfer function) was measured on the reference wind turbine and then applied to both turbines to calculate the free wind speed. For each of the two wind turbines, the power curve (PC) was measured with the met mast and the nacelle power curve (NPC) with the spinner anemometer. Four power curves (two PCs and two NPCs) were compared in terms of AEP (annual energy production) for a Rayleigh wind speed probability distribution. For each wind turbine, the NPC agreed with the corresponding PC within $0.10 \%$ of AEP for the reference wind turbine and within $0.38 \%$ for the second wind turbine, for a mean wind speed of $8 \mathrm{~m} \mathrm{~s}^{-1}$.
\end{abstract}

\section{Introduction}

Measuring the power performance of a wind turbine means establishing the relation between wind speed (input) and electric power (output). While the measurement of the electric power is straightforward (because it is already in electrical form), the challenge is to measure the wind speed. The IEC61400-12-1 standard describes the instrumentation requirements and the calculation procedures to determine the power curve with the method of bins, measuring the wind at hub height upstream of the wind turbine with a cup anemometer installed on a meteorological mast. A met mast is costly; therefore, the IEC61400-12-2 standard was developed to define requirements and procedures to measure the wind speed on the wind turbine. While the use of the nacelle anemometer (mounted on the nacelle roof) for performance measurements is a well-established procedure, the spinner anemometer is an option to measure the wind turbine performance with which few engineers have experience. A spinner anemometer (Pedersen, 2007) consist of three onedimensional sonic wind speed sensors mounted on the spinner of the wind turbine. The three sonic sensor signals are converted to the horizontal wind speed $U_{\text {hor }}$, the yaw misalignment $\gamma$ and the flow inclination angle $\beta$ with a conversion algorithm (Pedersen et al., 2015). The advantage of a spinner anemometer over a nacelle anemometer is that it is measuring in front of the rotor rather than behind, where the flow is influenced by the wake of the blades and other elements present on the nacelle as described by Frandsen et al. (2009).

The spinner anemometer must be traceably calibrated using a met mast in order to measure the wind speed accurately and to obtain an absolute power curve, according to the standard IEC61400-12-2 (2013) and as reported by Demurtas (2014).

Installation of a met mast for each wind turbine is obviously not viable. Therefore, the possibility of using the calibration found on a first-reference wind turbine with a spinner anemometer to another one of the same type was investigated in this work. 

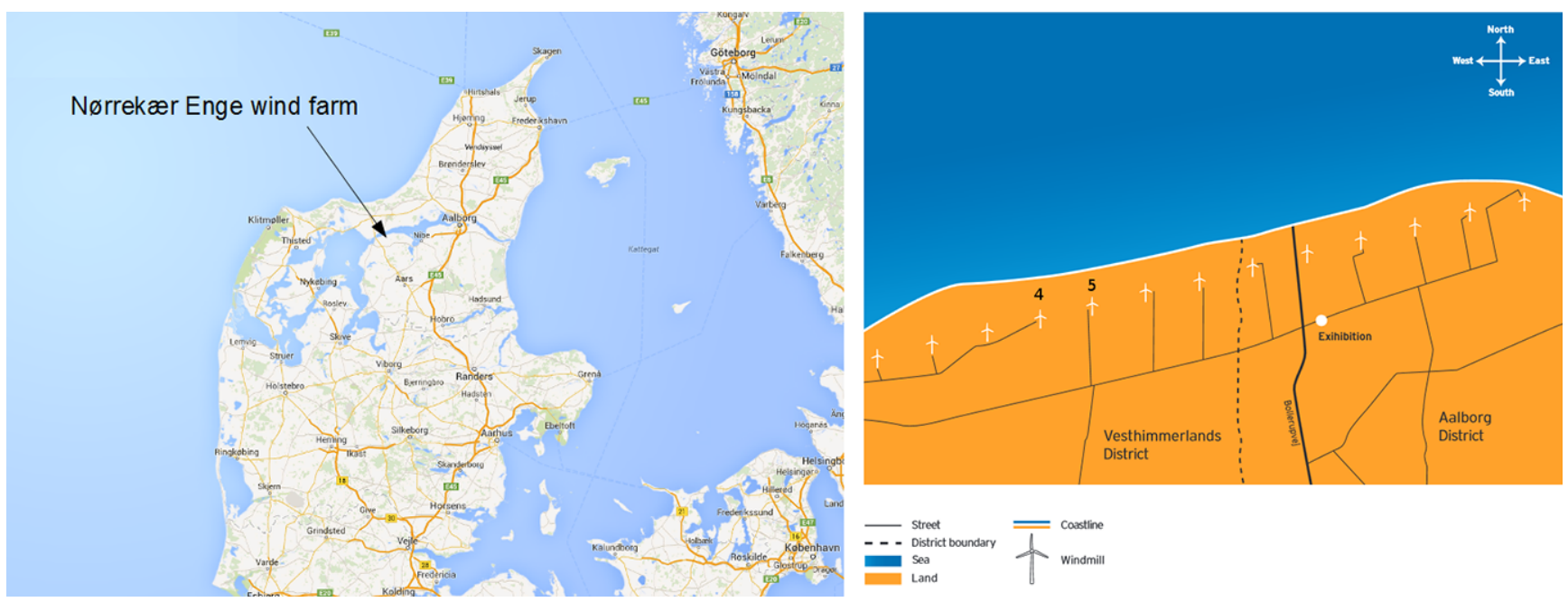

Figure 1. Left: location of the wind farm in Denmark. Right: location of the 13 wind turbines in the wind farm. The wind turbines are numbered 1 to 13 from left to right.

The steps to achieve the goals were as follows:

- Install a met mast to measure the power curve (PC) on two wind turbines next to each other.

- Install spinner anemometer on both wind turbines.

- Calibrate the spinner anemometer on the reference wind turbine.

- Measure the nacelle transfer function (NTF) on the reference wind turbine.

- Compute the NPC and PC for the reference wind turbine.

- Apply the calibration values and NTF measured on the reference wind turbine to the second wind turbine.

- Compute the NPC and PC for the second wind turbine.

- Compare the NPC with PC for both wind turbines.

- Evaluate the uncertainty related to spinner anemometer measurements.

All symbols used in the paper are explained in Appendix A, with additional abbreviations in Appendix B.

\section{Site description}

The measurements were taken at the Nørrekær Enge wind farm, located in the north of Denmark (Fig. 1, left panel). This wind farm consist of a row of 13 Siemens 2.3 MW wind turbines (Fig. 1, right panel) in a very flat site, each with a hub height of $80 \mathrm{~m}$ and rotor diameter of $93 \mathrm{~m}$. Every wind turbine was equipped with a spinner anemometer, but only the data from wind turbines 4 and 5 were used in

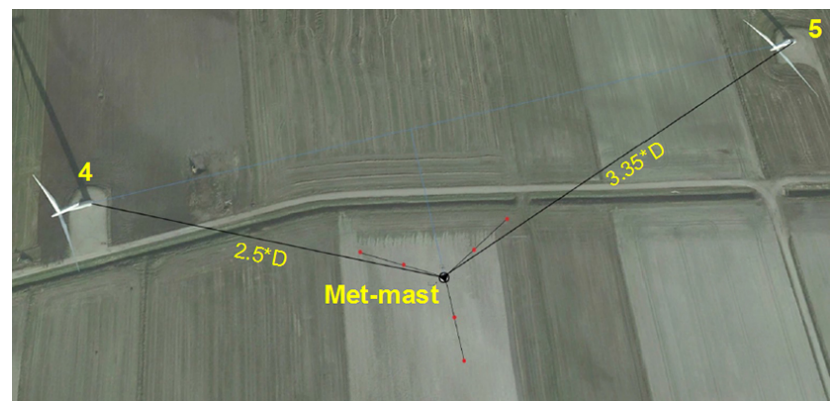

Figure 2. Relative position between reference wind turbine 4 , met mast and turbine 5 .

this work. For this experiment, an IEC61400-12-1 (2005)compliant met mast was erected near wind turbine 4 and 5 (Fig. 2).

The met mast was positioned 2.5 rotor diameters from wind turbine 4 and 3.35 rotor diameters from wind turbine 5 (Fig. 2). The met mast was equipped with a top-mounted cup anemometer at $80 \mathrm{~m}$ a.g.l. (above ground level) at hub height; a wind vane at $78 \mathrm{~m}$; and a barometer, thermometer and hygrometer at $78 \mathrm{~m}$ a.g.l.

The met mast used a data logger for meteorological measurements connected with a $3 \mathrm{G}$ modem to a server of DTU Wind Energy. In each wind turbine, spinner anemometers were connected to local data loggers with a $3 \mathrm{G}$ modems to a server of Romo Wind A/S. The electric power produced by the wind turbine was measured with additional voltage and current transducers and the same data logger used for the spinner anemometer (for more details see Demurtas, 2015). 


\section{Spinner anemometer calibration}

Calibration of spinner anemometers has been analyzed and investigated in Pedersen et al. (2015) and Demurtas et al. (2016). They found that the calibration chain for traceable wind speed measurements should include zero wind sensor path calibration, wind tunnel calibration, internal calibration, angle calibration, wind speed calibration and NTF. Details of the calibration procedures can be found in the references. Due to the large size of the spinner of a modern wind turbine it is not feasible to place it directly into a wind tunnel. Therefore each sonic sensor was first calibrated in the wind tunnel and then, once mounted on the spinner, internally calibrated (for details see the manual of the spinner anemometer by Metek $\mathrm{GmbH}, 2009)$. The internal calibration procedure ensures that the three sensors read the same average wind speed. The calibration value $k_{1}$ is related to wind speed measurements, whereas the calibration value $k_{\alpha}$ is related to flow angle measurements.

The spinner anemometer on $\mathrm{T} 4$ was $k_{\alpha}$ calibrated to ensure that the inflow angle is measured correctly, and $k_{1}$ calibrated to ensure that the output value $U_{\text {hor }}$ equals the free wind speed when the wind turbine is stopped and pointed to the wind (see Demurtas, 2014, for details). The $k_{\alpha}$ and $k_{1}$ calibration values found for $\mathrm{T} 4$ were used on both $\mathrm{T} 4$ and $\mathrm{T} 5$ (which is reasonable as long as the mounting of the sonic sensors and the spinner shapes is equal).

\subsection{Sonic sensors' wind tunnel calibration}

The objective of the calibration of individual sonic sensors is to calibrate the wind speed measurements by the sonic sensors $V_{1}, V_{2}$ and $V_{3}$. Each sensor was calibrated individually in a MEASNET-compliant wind tunnel. The sensor was mounted on a support plate to hold it in the wind tunnel test section (Fig. 3). The mounting plate geometry was defined in Demurtas (2014) and the procedure is described in IECRE (2015). A calibration certificate was released for each sonic sensor. The values resulting from the wind tunnel calibration (slope $m$, offset $q$ and sensor path angle $\phi_{\mathrm{s}}$; Table 1) should be set in the spinner anemometer conversion box (which converts $V_{1}, V_{2}, V_{3}$ and the rotor position into $U_{\text {hor }}, \gamma$ and $\beta$ ) with the method described in Demurtas (2014). Unfortunately, the wind tunnel calibrations were not set in the conversion box, and a tentatively correction was applied to the measurements afterwards (see Sect. 4).

\section{2 $k_{\alpha}$ calibration}

The calibration for inflow angle measurements was made with the wind speed response method (WSR) described in Demurtas and Janssen (2016). The wind turbine was yawed several times of plus minus $60^{\circ}$. The resulting calibration value $k_{\alpha}=1.442$ was used to correct the measurements with the procedure described in Pedersen et al. (2015). The uncer-

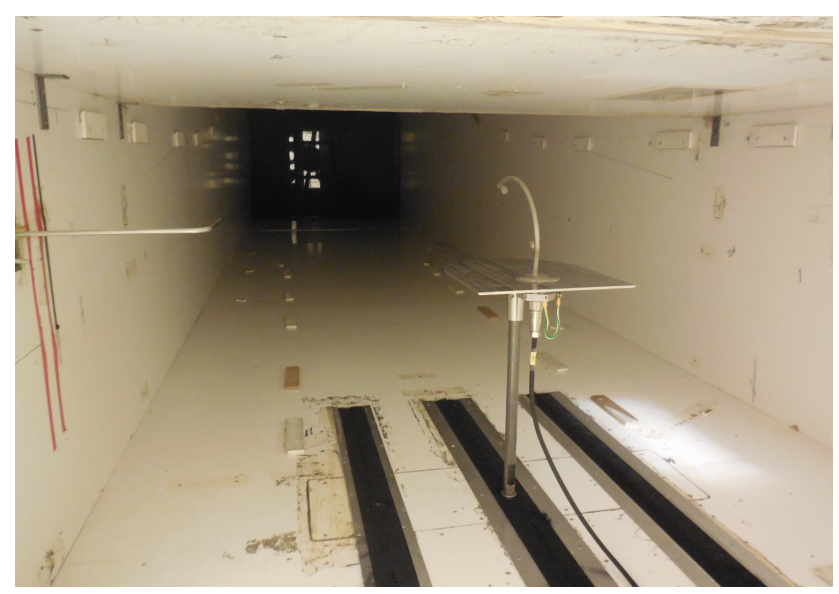

Figure 3. One sonic sensor mounted on the mounting plate in the test section of the SOHansen wind tunnel. The reference pitot tube is visible at the left-hand side of the photo.

tainty in the $k_{\alpha}$ value could be calculated by repeating the test several times (as was done in Demurtas and Janssen, 2016, which found a repeatability of the result within $8.5 \%$ of the mean value, for a different wind turbine model). In this case the calibration test was performed only once, and the uncertainty was estimated to $u_{k \alpha}=10 \% \cdot k_{\alpha}$.

\section{3 $k_{1}$ calibration}

The objective of this calibration is to find the value of the $k_{1}$ calibration constant that makes $U_{\text {hor }}$ to match the free wind speed $U_{\mathrm{mm}}$ when the wind turbine is stopped and is facing the wind. During operation of the wind turbine the rotor induction is accounted for with the nacelle transfer function (NTF) as described in the IEC61400-12-2 standard. To acquire the measurements needed for the calibration, the wind turbine should be stopped so that the wind seen by the spinner anemometer is not influenced by the induction. However, stopping the wind turbine would cause an energy loss; therefore, the calibration was performed with the wind turbine in operation at high wind speed as proposed by Demurtas et al. (2016).

The $k_{1}$ calibration procedure was based on measurements acquired during operation of the wind turbine where $k_{1}$ was set to the default value $k_{1, \mathrm{~d}}=1$ in the spinner anemometer conversion box. The correction factor $F_{1}$ was calculated as the ratio

$F_{1}=\frac{U_{\text {hor,d,c }}}{U_{\mathrm{mm}}}$,

where $U_{\text {hor,d,c }}$ is the horizontal wind speed measured with default $k_{1, \mathrm{~d}}$ and calibrated $k_{\alpha}$.

Since T4 is pitch-regulated, $F_{1}$ should tend to an asymptote as the wind speed increases (Fig. 4), because the induction decreases for high wind speed. The value of $F_{1}=0.6019$ was calculated as the average of the values for free wind 
Table 1. Sensor path angle $\left(\phi_{\mathrm{S}}\right)$, slope $(m)$ and offset $(q)$ coefficients of the sonic sensor wind tunnel calibrations.

\begin{tabular}{lrrr|rrr}
\hline & \multicolumn{2}{c|}{ Wind turbine 4 (SN: 107114721) } & \multicolumn{2}{c}{ Wind turbine 5 (SN: 107114722) } \\
\cline { 2 - 7 } & $m$ & $q$ & $\phi_{\mathrm{S}}$ & $m$ & $q$ & $\phi_{\mathrm{S}}$ \\
\hline Sensor 1 & 1.20746 & 0.18431 & $34.7^{\circ}$ & 1.22198 & 0.07906 & $34.7^{\circ}$ \\
Sensor 2 & 1.22794 & 0.00168 & $34.8^{\circ}$ & 1.23066 & -0.08116 & $34.6^{\circ}$ \\
Sensor 3 & 1.23249 & 0.16930 & $35^{\circ}$ & 1.21517 & -0.56490 & $34.1^{\circ}$ \\
\hline Average & 1.22263 & 0.11843 & $34.7^{\circ}$ & 1.22198 & 0.07906 & $34.7^{\circ}$ \\
\hline
\end{tabular}

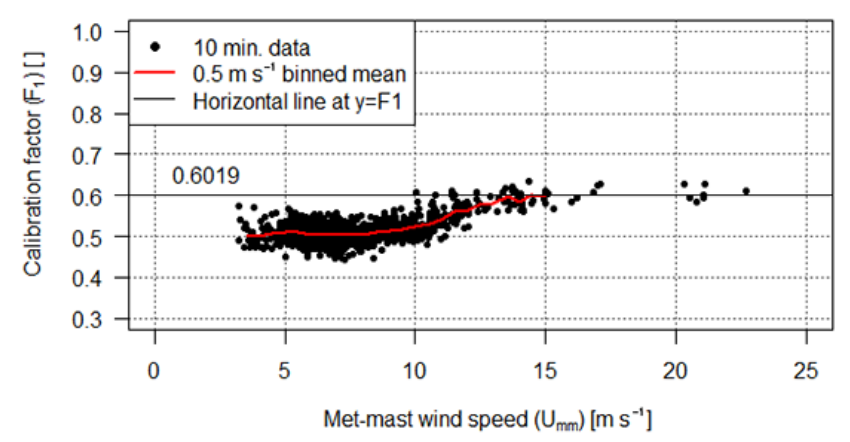

Figure 4. Calibration factor $F_{1}$ as a function of free wind speed during operation of the wind turbine.

speed greater than $15 \mathrm{~ms}^{-1}$. Since the default value was $k_{1, \mathrm{~d}}=1$, the calibration value is

$k_{1}=F_{1} \cdot k_{1, \mathrm{~d}}=0.6019$.

$k_{1}$ is not subject to uncertainty because it is compensated for by the uncertainty estimation of the NTF. This is further explained in Sect. 9.

\section{Measurement database, data filtering and corrections}

The measurement database consists of $237 \mathrm{~h}$ of measurements acquired in a free wind direction sector between 101 and $229^{\circ}$ as measured by the wind vane on the met mast based on $10 \mathrm{~min}$ averages. The spinner anemometer measurements from both wind turbine 4 and 5 were calibrated with the $k_{\alpha}$ and $k_{1}$ values found for T4. Ten-minute datasets, where the minimum wind turbine rotor rotational speed was lower than $40 \mathrm{rpm}$, were filtered out in order to keep data where the wind turbine is continuously in operation. Datasets where the 10 min mean power coefficients (measured with the met mast) were higher than 16/27 (the Betz limit) were filtered out to remove four outliers (this is a deviation to the requirements of the IEC61400-12-1, 2005, standard). There was no need to filter for freezing temperature since the temperature was between 6 and $14^{\circ} \mathrm{C}$.

The wind tunnel calibration values of the sonic sensors were not set in the spinner anemometer conversion box, as re- quired in Demurtas (2014). However, a correction was made on the measurements to take the results of the wind tunnel calibration into account. From the calibration certificates (Table 1) the sensors on wind turbine 5 have on average smaller slope coefficients $\left(m_{5}\right)$ and smaller offsets $\left(q_{5}\right)$ than those on T4 ( $m_{4}$ and $\left.q_{4}\right)$, which means that the sensors on T5 are reading slightly higher wind speeds than sensors on T4 (with the default $k_{1, \mathrm{~d}}$ and $k_{\alpha, \mathrm{d}}$ values). Measurements of T5 were therefore corrected with the ratio of the mean slope and the difference in mean offset.

$U_{5}=U_{5, \text { original }} \cdot\left(m_{5} / m_{4}\right)+q_{5}-q_{4}$,

where $U_{5}$,original is the horizontal wind speed measurements of T5; $U_{5}$ is the horizontal wind speed of wind turbine 5 corrected for wind tunnel calibration; and $m_{4}, m_{5}, q_{4}$, and $q_{5}$ are average slope and offset values from the calibrations.

Figure 5 shows the 10 min mean values of power and calibrated wind speed. The wind speed was normalized with a value between 10 and $14 \mathrm{~m} \mathrm{~s}^{-1}$ to not disclose the absolute power performance of the wind turbine, which is confidential information.

The traceability of the measurements of the spinner anemometer on T4 was ensured by the calibrated met-mast instruments and the NTF, while the traceability of the spinner anemometer on T5 was ensured by the NTF and wind tunnel calibration of the sonic sensors.

The air density was calculated from the met-mast measurements with Eq. (4) (from IEC61400-12-2, 2013), where $P_{w}=0.0000205 \cdot e^{(0.06138467 \cdot T)}, \quad R_{0}=287.05 \mathrm{~J} \mathrm{~kg}^{-1} \mathrm{~K}^{-1}$, and $R_{w}=461.5 \mathrm{~J} \mathrm{~kg}^{-1} \mathrm{~K}^{-1} . T$ is expressed in kelvin and $P$ in absolute pascal:

$\rho=\frac{1}{T}\left(\frac{P}{R_{0}}-\mathrm{RH} \cdot P_{w}\left(\frac{1}{R_{0}}-\frac{1}{R_{w}}\right)\right)$.

Measured air density was between 1.2 and $1.27 \mathrm{~kg} \mathrm{~m}^{-3}$.

\section{Nacelle transfer function measurement}

The purpose of the NTF is to correct the spinner anemometer measurements to be representative of the free wind speed. $U_{\mathrm{mm}}$ is the free wind speed measured by the met mast, and $U_{\text {free }}$ is the free wind speed calculated by correcting the spinner anemometer measurements $\left(U_{\text {hor }}\right)$ with the NTF. 

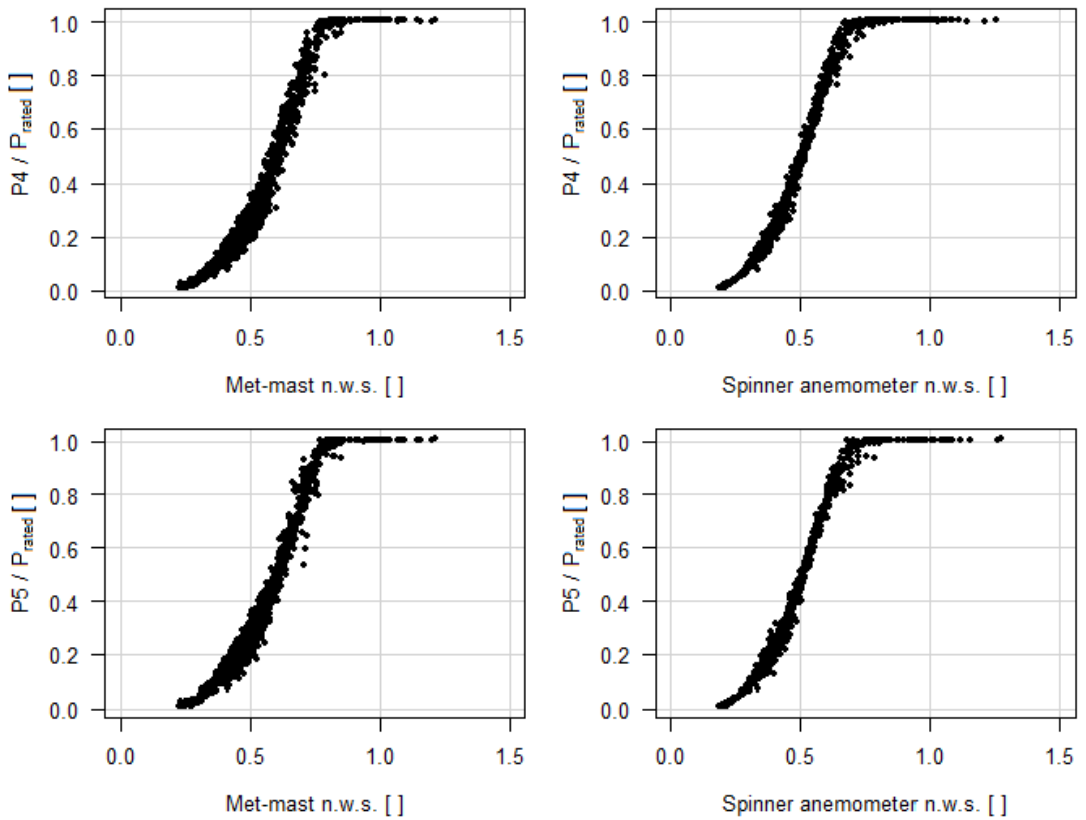

Figure 5. Scatter plot of 10 min averages of power as a function of spinner anemometer normalized wind speed (n.w.s.) and met-mast normalized wind speed measurements, for wind turbines 4 and 5, before application of the NTF and before air density correction. Met-mast measurements to the left, and spinner anemometer measurements to the right. Turbine 4 measurements upper and turbine 5 measurements lower. Data refer to the same measurement period. P4 is the power output of wind turbine 4, and P5 is the power output of wind turbine 5 .

The IEC61400-12-2 (2013) standard defines the NTF as the met-mast wind speed binned as a function of the nacelle wind speed. Krishna et al. (2014) investigated the root cause for high deviations in the self-consistency check with the IEC61400-12-2 (2013) method and proposed an improved method, which consist of binning the spinner anemometer wind speed as a function of the met-mast wind speed. This procedure is used here. If a wind speed bin has less than three measurements, the value of the NTF is calculated by linear interpolation from the adjacent bins if they both have at least three measurements each. No air density correction was made for the measurement of the NTF. The measured NTF for the spinner anemometer installed on T4 is shown in Fig. 6 .

The NTF is close to the $1: 1$ line at high wind speed (around $11-15 \mathrm{~m} \mathrm{~s}^{-1}$, on which the $k_{1}$ calibration is based), and is lower than 1:1 for the range of wind speeds where the wind turbine is operating with high $\mathrm{Cp}$ (high induction, which makes the wind speed by the spinner anemometer lower than the free wind speed).

\section{NTF self-consistency check}

The black line in Fig. 7 shows the power difference between the PC and the NPC of wind turbine 4. The blue and red curves shows the pass/fail boundaries defined in IEC6140012-2 (2013) for the NTF. Both power curves were interpo-

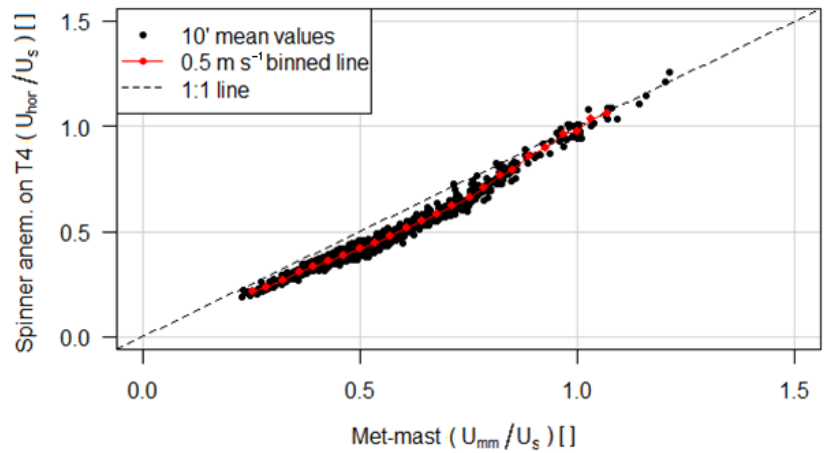

Figure 6. Nacelle transfer function measured with the spinner anemometer of wind turbine 4 . Red line is the NTF obtained by linear interpolation between the red dots, which are the NTF binned values.

lated to the center of the bin with a cubic spline, ${ }^{1}$ so that the power values for the two power curves correspond to the same wind speed. Krishna et al. (2014) claimed that a NPC calculated from the same dataset used to measure the NTF (as it is the case for wind turbine 4) is identical to the PC (and therefore the self-consistency check should return zero power difference for any wind speed bin). However, in the present calculations the power difference was not zero. The

\footnotetext{
${ }^{1}$ As suggested in the draft of IEC61400-12-1, 88/460/CD, regarding presenting a power curve with values interpolated to the center of the bin.
} 


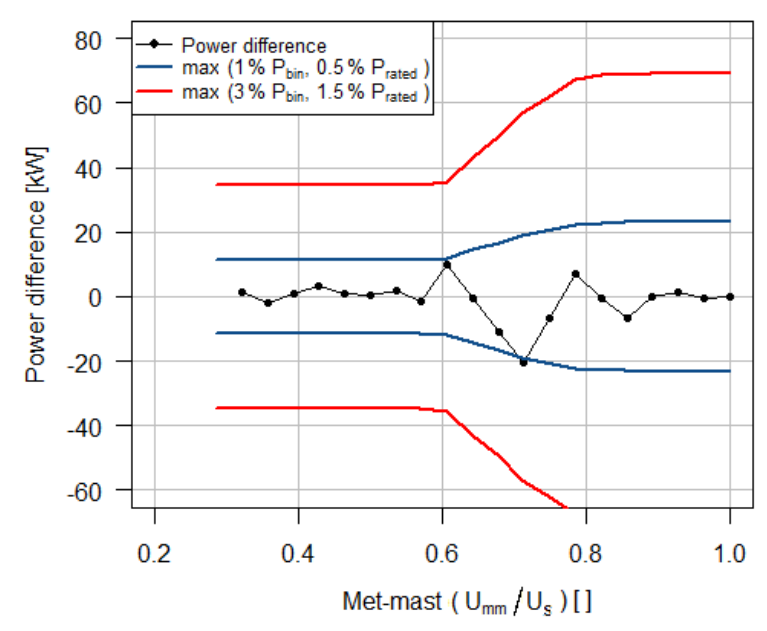

Figure 7. Nacelle transfer function self-consistency check. The black curve shows the power difference between NPC and PC of the wind turbine used to measure the NTF. The NTF passes the test if the black curve is within the boundary marked by the blue curve. If the black curve crosses the red curve a new NTF should be measured. $P_{\text {bin }}$ is the averaged power in a wind speed bin. $P_{\text {rated }}$ is rated power.

PC was binned according to the met-mast wind speed $\left(U_{\mathrm{mm}}\right)$, and the NPC was binned according to the corrected nacelle wind speed ( $\left.U_{\text {free }}\right)$. Krishna et al. (2014) suggested to bin both PC and NPC according to $U_{\mathrm{mm}}$ to keep uniformity in the binning process, but doing so would mean binning the exact same measurements for NPC and PC, which obviously results in the same binned values of power.

As mentioned, Krishna et al. (2014) suggest to bin the NTF-corrected nacelle wind speed according to the met-mast wind speed $U_{\mathrm{mm}}$ to check the validity of the NTF. In the normal use of the NTF the met mast is not available, and the power curve would be binned according to $U_{\text {free }}$. The procedure to calculate a NPC should be the same on the reference wind turbine (where the NTF was measured and verified with the self-consistency check) and on other wind turbines. Therefore, it makes more sense to always calculate the binaveraged power curve binning according to $U_{\text {free }}$. In the procedure used in the present analysis, the bin average of the NTF-corrected nacelle wind speed $U_{\text {free }}$ are different from the bin average of the measured free wind speed $U_{\mathrm{mm}}$ (binning both according to $U_{\mathrm{mm}}$ ). The cause is explained as follows.

The bin averages are computed by binning according to the same $U_{\mathrm{mm}}$; therefore, the binning itself should not make a difference. The spinner anemometer measurements that fall outside the range of the definition of the NTF are lost during the application of the NTF. Therefore, the bin average of those outermost bins will most likely be different from the original bin average value. One more reason for the bin average values to be different is that the correction applied with the NTF is applied to the time series through a linear inter- polation, not to the bin average value. The binned values of $U_{\text {free }}$ and $U_{\mathrm{mm}}$ would be equal only if the NTF correction was constant for all the measurements of the bin with a value corresponding to the NTF. When the NTF is applied to the time series, the slopes of the linear interpolation segments are different on the two sides of the NTF definition point in a certain bin $i$. The black curve in Fig. 7 does in fact pass the blue curve. The cause of this is that the difference on $U_{\text {free }}$ and $U_{\mathrm{mm}}$ is maximized in the significant slope of the power curve just before it reaches nominal power.

\section{Application of the nacelle transfer function}

The NTF, measured on wind turbine 4, was applied on spinner anemometer measurements of wind turbine 4 and then on wind turbine 5. Linear interpolation was used between the points that defines the NTF as described in the IEC6140012-2 (2013) standard. The measurements that fall outside the range of the definition of the NTF are lost since the NTF is undefined for these measurements. With the application of the NTF, some of the measurements were lost because the NTF was not defined above a certain wind speed (in Fig. 6 the red line does not extend as much as the black points; therefore, about $2.5 \mathrm{~h}$ of measurements are lost out of $237 \mathrm{~h}$ ).

The relation between free wind speed measured from the met mast $U_{\mathrm{mm}}$ and free wind speed calculated from spinner anemometer measurements $U_{\text {free }}$ is shown in the scatter plot of Fig. 8 for wind turbines 4 and 5 .

Since the spinner anemometer was calibrated for wind speed measurements following the method described in Sect. 3.3, the spinner anemometer wind speed measurements already match the met-mast wind speed at high wind speeds $\left(U>13 \mathrm{~m} \mathrm{~s}^{-1}\right)$, that is, when the rotor induction is low. From Fig. 9 we can see that the correction applied by the NTF is mostly localized below rated wind speed.

\section{Power curves and AEP}

The calculated free wind speed $U_{\text {free }}$ and measured free wind speed at the mast $U_{\mathrm{mm}}$ were corrected to standard air density of $1.225 \mathrm{~kg} \mathrm{~m}^{-3}$ with Eq. (5) after application of the NTF. This is in accordance with IEC61400-12-2 (2013) for a pitchregulated wind turbine.

$U_{\text {free }, n}=U_{\text {free }}\left(\frac{\rho}{1.225}\right)^{1 / 3}$

The met-mast power curve was similarly corrected to standard air density with Eq. (6) in accordance with IEC6140012-1 (2005) for a pitch-regulated wind turbine.

$U_{\mathrm{mm}, n}=U_{\mathrm{mm}}\left(\frac{\rho}{1.225}\right)^{1 / 3}$

The power curves of wind turbines 4 and 5 were obtained by averaging the power in each wind speed bin of $0.5 \mathrm{~m} \mathrm{~s}^{-1}$ (see 

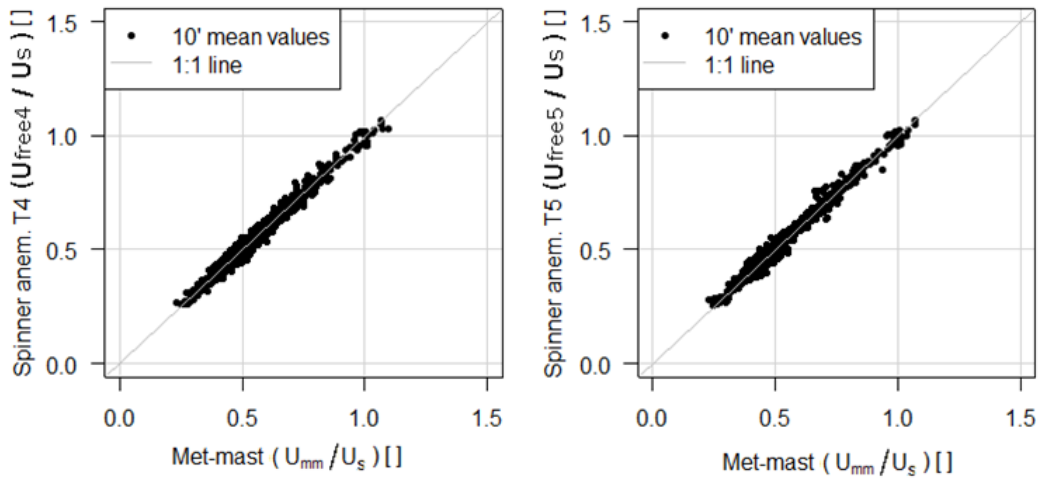

Figure 8. Calculated free wind speed as a function of measured free wind speed. Wind turbine 4 to the left and wind turbine 5 to the right. $R_{\mathrm{T} 4}^{2}=0.9840, R_{\mathrm{T} 5}^{2}=0.9846$.
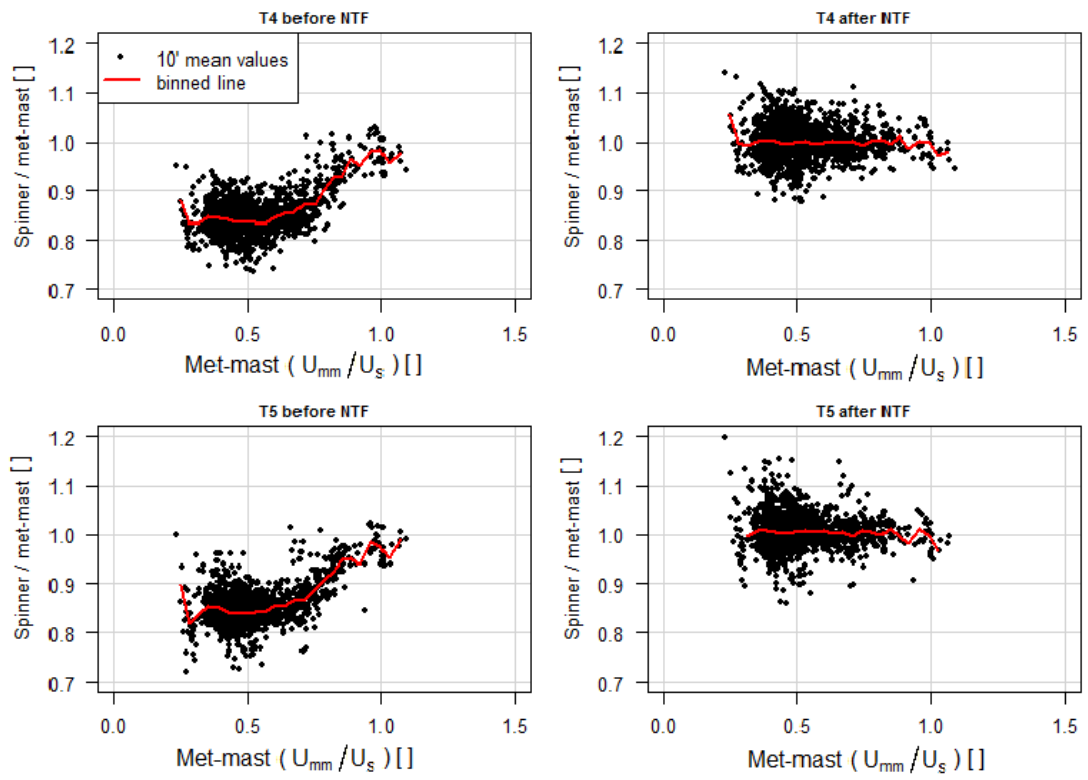

Figure 9. Ratio between calculated free wind speed and measured free wind speed $\left(U_{\mathrm{free}} / U_{\mathrm{mm}}\right)$ as a function of measured free wind speed $\left(U_{\mathrm{mm}}\right)$. Upper left: wind turbine 4 before application of the NTF. Upper right: wind turbine 4 after application of the NTF. Lower left: wind turbine 5 before application of the NTF. Lower right: wind turbine 5 after application of the NTF.

Fig. 10). The value of power was interpolated with a cubic spline to the center of the wind speed bin so that the power values of the four power curves are comparable (they all refer to the center of the wind speed bins).

Figure 10 shows the four power curves: NPC for T4, PC for T4, NPC for T5, and PC for T5.

A measure of the difference between the curves was evaluated by calculating the annual energy production (AEP) for a Rayleigh wind speed distribution with annual average wind speed between 4 and $11 \mathrm{~m} \mathrm{~s}^{-1}$. Table 2 shows the difference in AEP estimated for the four power curves. The AEP was calculated for the extrapolated power curve up to $25 \mathrm{~m} \mathrm{~s}^{-1}$.

The nacelle power curve of wind turbine 4 was compared with the met-mast power curve and was within $0.10 \%$ AEP of the met-mast power curve at $8 \mathrm{~m} \mathrm{~s}^{-1}$ average wind speed.
The corresponding comparison of the nacelle power curve of wind turbine 5 with the met mast was within $0.38 \%$ (see Table 2). The NPC is not identical to the PC, and the binned values of $U_{\text {free }}$ are not equal to the binned values of $U_{\mathrm{mm}}$ even when binning both according to $U_{\mathrm{mm}}$.

As expected, PC4 with NPC4 compares better than PC5 with NPC5 since the NTF was measured on T4. The uncertainty in AEP calculated for PC4 in the DTU report I0440 (Demurtas, 2015) (the report analyzed measurements of the same wind turbines of the present article; however, the measurements were not normalized, so the report contains confidential information regarding the wind turbine performance and is not publicly available) was found to be $14.2 \%$ for $V_{\text {avg }}=4 \mathrm{~m} \mathrm{~s}^{-1}, 5.7 \%$ for $V_{\text {avg }}=8 \mathrm{~m} \mathrm{~s}^{-1}$ and $4.2 \%$ for 
Table 2. Comparison between met-mast power curve (PC) and nacelle (spinner) power curve (NPC) in terms of annual energy production. The values in the table are calculated as (from/to -1$) \cdot 100$. The AEP was calculated with the extrapolated power curve from valid data to $25 \mathrm{~m} \mathrm{~s}^{-1}$.

\begin{tabular}{r|rrrrr}
\hline$V_{\text {avg }}$ & $\begin{array}{r}\text { From: } \\
\text { to: }\end{array}$ & $\begin{array}{r}\text { NPC4 } \\
\text { PC4 }\end{array}$ & $\begin{array}{r}\text { NPC5 } \\
\text { PC5 }\end{array}$ & $\begin{array}{r}\text { PC5 } \\
\text { PC4 }\end{array}$ & $\begin{array}{r}\text { NPC5 } \\
\text { NPC4 }\end{array}$ \\
\hline $\mathrm{m} \mathrm{s}^{-1}$ & & $\%$ & $\%$ & $\%$ & $\%$ \\
\hline 4 & & 0.10 & -1.35 & -1.04 & -2.47 \\
5 & & 0.14 & -0.95 & -0.74 & -1.82 \\
6 & & 0.13 & -0.69 & -0.55 & -1.37 \\
7 & & 0.12 & -0.51 & -0.44 & -1.06 \\
8 & & 0.10 & -0.38 & -0.36 & -0.84 \\
9 & & 0.09 & -0.30 & -0.31 & -0.69 \\
10 & & 0.07 & -0.24 & -0.28 & -0.59 \\
11 & & 0.07 & -0.19 & -0.25 & -0.51 \\
\hline
\end{tabular}

$V_{\text {avg }}=11 \mathrm{~m} \mathrm{~s}^{-1}$. The AEP difference is more than 10 times smaller than the AEP uncertainty.

\section{Uncertainty analysis}

This section will describe the evaluation of uncertainty in the free wind speed measured with the met mast, as well as the free wind speed calculated with an NTF applied to spinner anemometer measurements. The combination of uncertainties is made according to GUM (Guide to the expression of uncertainty in measurements, JCGM/WG1, 2008). The spinner anemometer measures the wind speed by means of three sonic sensors and a conversion algorithm (Pedersen et al., 2015). Each sensor was calibrated independently in a MEASNET-compliant wind tunnel. The uncertainties in the three velocities were combined through the spinner anemometer conversion algorithm to give the uncertainty in the horizontal wind speed.

The uncertainty in spinner anemometer on $\mathrm{T} 4$ due to differences in mounting of the three sonic sensors is zero, since this spinner anemometer was used to measure the NTF. The mounting of the second spinner anemometer (on T5) was compared with the mounting of the reference spinner anemometer (on T4), and an additional uncertainty due to mounting differences with respect to $\mathrm{T} 4$ was added to the measurements of the spinner anemometer on T5.

\subsection{Uncertainty related to wind tunnel calibration of sonic sensors}

The relation between the wind tunnel speed and the velocity component in the sensor path is

$V_{1}=V_{\mathrm{t}} \cdot \cos \left(\phi_{\mathrm{s}}\right)$.

If the angle $\phi_{\mathrm{s}}$ of the sonic sensor path with respect to the horizontal mounting plate was not measured, one should

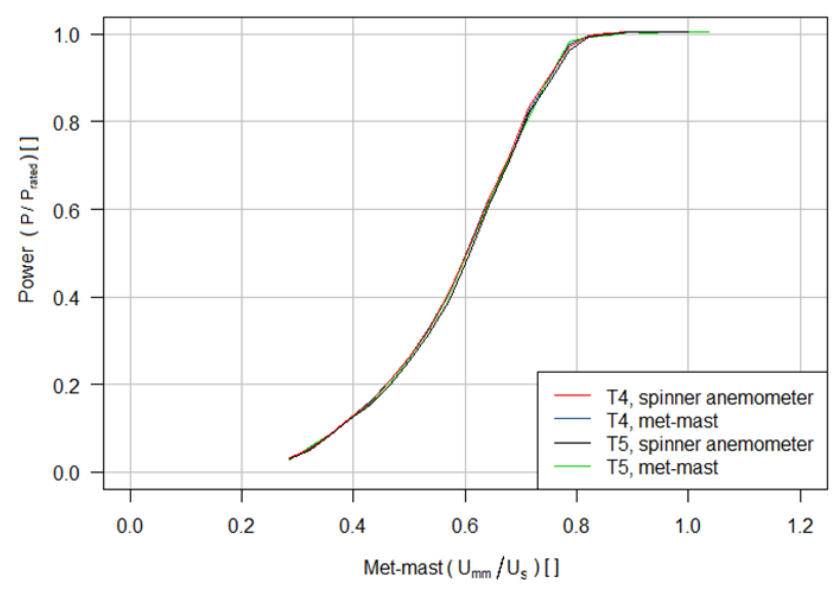

Figure 10. Power curves of wind turbines 4 and 5, measured with met mast and with spinner anemometer.

assume that $\phi_{\mathrm{S}}$ is within the manufacturing tolerance, $\phi_{\mathrm{s}}=$ $35^{\circ} \pm 1.5^{\circ}$. The standard uncertainty in $\phi_{\mathrm{s}}$ can therefore be expressed by the standard deviation of the tolerance, considered to represent a rectangular uncertainty distribution:

$u_{\phi_{\mathrm{s}}}=(36.5-33.5) /(2 \sqrt{3})=0.866^{\circ}$.

In this case the angle $\phi_{\mathrm{S}}$ was measured as part of the wind tunnel calibration (see Table 1). The uncertainty in $\phi_{\mathrm{s}}$ depends on the accuracy of the protractor (the instrument to measure angles). In this case, a digital protractor with an accuracy of $0.2^{\circ}$ was used, and therefore $u_{\phi_{\mathrm{s}}}=0.2^{\circ}$ was used instead of $0.866^{\circ}$.

The uncertainty in the wind tunnel calibration was expressed in the calibration certificates for a coverage factor $k_{\mathrm{c}}=2$ as a binned value as a function of wind tunnel speed. While the uncertainty is typically almost constant for a cup anemometer, the sonic sensor uncertainty showed an increase with wind speed. The standard uncertainty $\left(k_{\mathrm{c}}=1\right)$ was calculated by dividing the value reported in the certificates by two. The calibration standard uncertainty (function of wind speed) was fitted to a line as shown in Eq. (9).

$u_{\mathrm{t}}=\left(2.24 \cdot V_{i}+0.855\right) \cdot 10^{-3} \mathrm{~m} \mathrm{~s}^{-1}$

The uncertainty in the sonic sensor velocity $V_{1}$ is obtained combining the uncertainty $u_{\mathrm{t}}$ with the uncertainty $u_{\phi_{\mathrm{s}}}$, using the equation for combination of uncertainty in independent variables as expressed in Eq. (10) (according to Sect. 5.1.2 of the GUM, JCGM/WG1, 2008) and also shown in the IECRE (2015) clarification sheet.

$u_{\mathrm{c}}^{2}(y)=\sum_{i=1}^{N}\left(\frac{\partial f}{\partial x_{i}}\right)^{2} u^{2}\left(x_{i}\right)$ 

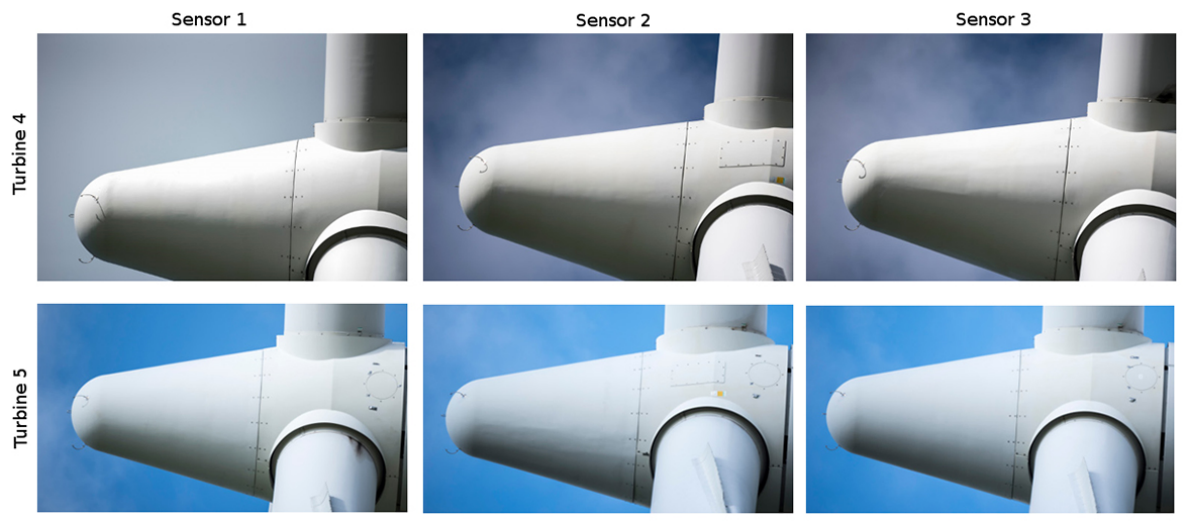

Figure 11. Photos of two spinner anemometers (wind turbine 4 above, wind turbine 5 below; sensors 1,2 and 3 from left to right).

Equation (10) applied to Eq. (7) results in Eq. (11):

$$
\begin{aligned}
u_{1}^{2} & =\left(\frac{\partial\left(V_{\mathrm{t}} \cos \phi_{\mathrm{s}}\right)}{\partial V_{\mathrm{t}}}\right)^{2} u_{\mathrm{t}}^{2}+\left(\frac{\partial\left(V_{\mathrm{t}} \cos \phi_{\mathrm{s}}\right)}{\partial \phi_{\mathrm{s}}}\right)^{2} u_{\phi_{\mathrm{s}}}^{2} \\
& =\cos ^{2} \phi_{\mathrm{s}} \cdot u_{\mathrm{t}}^{2}+V_{\mathrm{t}}^{2} \sin ^{2} \phi_{\mathrm{s}} \cdot u_{\phi_{\mathrm{s}}}^{2},
\end{aligned}
$$

with $u_{\mathrm{t}}$ (Eq. 9) as the uncertainty in the wind tunnel wind speed and $u_{\phi_{\mathrm{s}}}$ as the uncertainty in the sensor path angle (Eq. 8 or uncertainty in the protractor). The combined uncertainty in $V_{1}$ due to wind tunnel calibration is

$u_{1}=\sqrt{\left(\cos \phi_{\mathrm{s}}\right)^{2} \cdot u_{\mathrm{t}}^{2}+\left(V_{\mathrm{t}} \cdot \sin \phi_{\mathrm{s}}\right)^{2} \cdot u_{\phi_{\mathrm{s}}}^{2}}$.

The same applies to each of the sensors $\left(u_{2}, u_{3}\right)$.

\subsection{Evaluation of spinner anemometer mounting}

The three sonic sensors should be mounted on the spinner with the best possible rotational symmetry and equal distance from the spinner's center of rotation. A visualization method for documentation of the sonic sensors installations was developed by Demurtas and Pedersen with the use of photography (Demurtas, 2015). The initial mounting of the sensors was used for the first power curve measurements reported in Demurtas (2015). The accuracy of sensor mounting was then improved and the power curve measurement repeated and reported in this work. The mounting position was evaluated using the photography method described in Demurtas (2015). Due to the challenge of photographing a feature of size on the order of centimeters (the sonic sensor) from a long distance ( $80 \mathrm{~m}$ from ground to spinner) we used a $400 \mathrm{~mm}$ optical zoom lens and a high-resolution digital camera (24 megapixels).

Several photos of the spinner were taken from the ground during rotation of the wind turbine and three photos were selected each time a sonic sensor is visible on the side of the spinner, with the sky in the background.
Each of the six photos (three for each wind turbine, Fig. 11) was post-processed to make it semi-transparent. The photos were overlayed, scaled and rotated in order to make the spinner contour match. The sky was made transparent and a contrasting red background was added (Fig. 12).

The photo overlay was scaled to make the sonic sensor path $16.7 \mathrm{~cm}$ long, like it is in reality. The positions of the sonic sensors on the spinner were measured in the plane of the photos as the angle between a plane perpendicular to the spinner axis and the sensors of extreme forward and backward positions. The positions of the sensor paths were measured on the photo with a vector graphic software program (inkscape).

The improved mounting of the sensors showed a mounting accuracy in the order of $\pm 2 \mathrm{~cm}$. This was an improvement of the initial mounting, whose accuracy was $\pm 6 \mathrm{~cm}$. The sensors of the two wind turbines fell into a mounting angle interval $\left[a_{-}, a_{+}\right]=\left[31,40^{\circ}\right]$ for the old mount and $\left[48,51^{\circ}\right]$ for the improved new mount. For practical reasons (so as not to interfere with the old mounting holes), in the improved mount the sensors were also moved forward on the spinner.

\subsection{Uncertainty in wind speed measurements due to mounting imperfections}

The uncertainty connected to the error in mounting position of the sonic sensor was investigated by approximating the spinner as a sphere and using potential flow theory to calculate the flow around a sphere. The mean air velocity along the sensor path was calculated by averaging the wind velocity component along the sensor path in three points along the path (points shown with black or red dots in Fig. 13).

The flow field was calculated for a mesh of $0.01 \mathrm{~m}$ in the $x$ and $y$ direction. The coordinates of each point were converted from Cartesian coordinates $\left(x_{p}, y_{p}\right)$ to polar coordinates $(r, \theta)$ with Eqs. (13) and (14). An angle of $\pi / 2$ was added to the $\theta_{p}$ coordinate (Eq. 14) to rotate the result in order to have the flow coming from the left parallel to the $x$ 


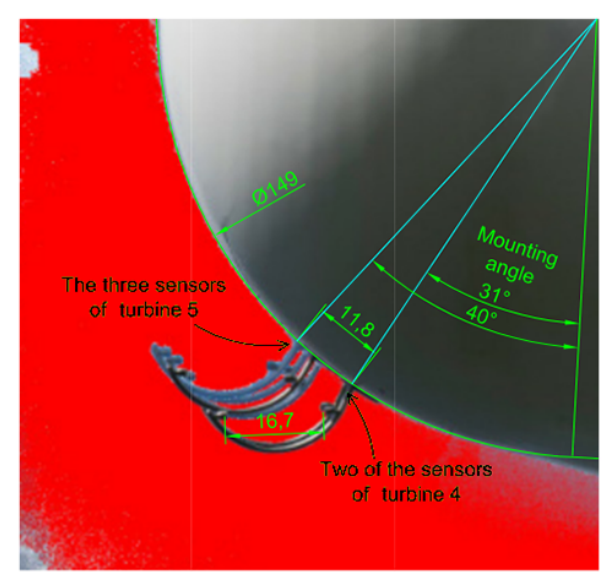

(a) Old mount

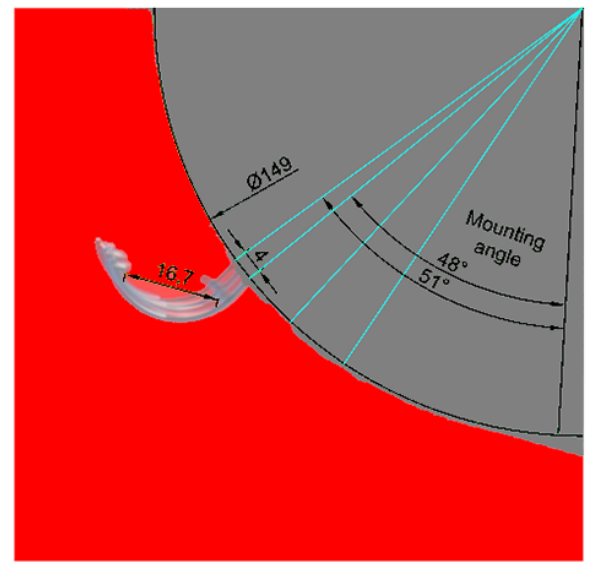

(b) New mount

Figure 12. Sonic sensors' relative mounting position between wind turbine 4 and wind turbine 5 (not to scale; dimensions are in centimeters). Left: original mounting. Right: after improvement of the mounting accuracy. The blue lines connect the center of the spinner sphere with the extreme mounting position of the sensors. In the figure at the right-hand side, four blue lines show the position of the original and improved mounting.

axis. This also rotated the origin of the angles to the vertical axis, which is convenient to measure the position of the mounting angles of the sonic sensors.

$r=\sqrt{\left(x_{p}^{2}+y_{p}^{2}\right)}$

$\theta_{p}=\arctan \left(y_{p} / x_{p}\right)+\pi / 2$

The potential flow model is oriented such that the inflow is parallel to the spinner axis of rotation; therefore, $U=U_{\text {hor }}=$ $U_{0}$. The flow field was calculated in polar coordinates with Eq. (15) (along radius) and Eq. (16) (perpendicular to radius) with the equations by Faith and Morrison (2013).

$v_{\mathrm{r}}=U_{0}\left[1-(R / r)^{3}\right] \cos \left(\theta_{p}\right)$

$v_{\mathrm{t}}=-U_{0}\left[1+0.5 \cdot(R / r)^{3}\right] \sin \left(\theta_{p}\right)$

The modulus of the wind speed was calculated with Eq. (17) and shown with the color scale in Fig. 13.

$U=\sqrt{\left(v_{\mathrm{r}}^{2}+v_{\mathrm{t}}^{2}\right)}$

The air velocity along the sensor path at the point $p(r, \theta)$ was calculated with Eq. (18), where $\phi_{\mathrm{S}}=35^{\circ}$ is the default angle between the sensor path and the sensor root (tangent to the spinner surface).

$U_{p}=v_{\mathrm{r}} \cdot \sin \left(\phi_{\mathrm{s}}\right)-v_{\mathrm{t}} \cdot \cos \left(\phi_{\mathrm{s}}\right)$

Equation (18) was used to calculate the wind velocity along the sensor path in each of the black points shown in Fig. 13. Then, the mean wind speed along each sensor path was calculated as an average value of the velocity along the sensor path in the three points related to each sensor path (Eq. 19).

$U_{\text {path }}=\frac{U_{p_{1}}+U_{p_{2}}+U_{p_{3}}}{3}$

The sensor path wind speed was calculated for each of the four sensor mounting positions measured with the photographic method of Fig. 12 and is presented in Table 3. The sensor path wind speed was normalized to the wind speed upstream of the spinner $\left(U_{0}\right)$. The uncertainty due to mounting imperfections is a type B uncertainty ("Guide to the expression of uncertainty in measurements") (JCGM/WG1, 2008, Sect. 4.3.1 and 4.3.7). The probability of the sonic sensor wind velocity to be within the interval $a_{-}$to $a_{+}$calculated from the positions identified with the photographic method is equal to one and the probability that it lies outside the interval is zero. There is no particular reason for the sensor path wind velocity to fall into the interval in a particular position. Therefore, we can assume that the probability that the sensor path wind speed is within the interval is a rectangular distribution. This means that the standard uncertainty is

$u_{\mathrm{m}}=\left(a_{+}-a_{-}\right) /(2 \sqrt{3})$.

The uncertainty is a value relative to the wind speed upstream of the spinner anemometer $\left(U_{\text {hor }}\right)$. This uncertainty does not apply to wind turbine 4 , which was used to measure the NTF.

\subsection{Combination of uncertainties through the spinner anemometer conversion algorithm}

This section will explain how to combine the uncertainty in the input quantities to obtain the uncertainty in the output of the spinner anemometer: the horizontal wind speed. The 
Table 3. Mounting angles, sensor path wind speed and uncertainty due to mounting accuracy.

\begin{tabular}{|c|c|c|c|c|}
\hline & \multicolumn{2}{|c|}{ Initial mount } & \multicolumn{2}{|c|}{ Improved mount } \\
\hline Mounting angle & $31^{\circ}$ & $40^{\circ}$ & $48^{\circ}$ & $51^{\circ}$ \\
\hline Sensor path relative speed $\left(U_{\text {path }} / U_{0}\right)$ & $a_{+}=0.9864$ & $a_{-}=0.8940$ & $a_{+}=0.7934$ & $a_{-}=0.7516$ \\
\hline Uncertainty in sensor path wind speed $\left(u_{\mathrm{m}}\right)$ & \multicolumn{2}{|c|}{$2.7 \% U_{\text {hor }}$} & \multicolumn{2}{|c|}{$1.2 \% U_{\text {hor }}$} \\
\hline
\end{tabular}

uncertainty in $U_{\text {hor }}$ is the combination of the following uncertainty components:

- $u_{1}$, sensor 1 wind tunnel calibration (which includes $u_{\mathrm{t}}$ and $\left.u_{\phi_{\mathrm{s}}}\right)$

- $u_{2}$, sensor 2 wind tunnel calibration (which includes $u_{\mathrm{t}}$ and $\left.u_{\phi_{\mathrm{s}}}\right)$

- $u_{3}$, sensor 3 wind tunnel calibration (which includes $u_{\mathrm{t}}$ and $\left.u_{\phi_{\mathrm{s}}}\right)$;

- $u_{\mathrm{m}}$, sensor mounting;

- $u_{k_{\alpha}}$, angular calibration.

The uncertainty in $k_{1}$ is $u_{k 1}=0$ because all the uncertainty related to wind speed is included in the uncertainty in the NTF ( $u_{\mathrm{NTF}}$; see Sect. 9.7). The uncertainties in the sonic sensor speeds $\left(u_{1}, u_{2}\right.$ and $\left.u_{3}\right)$ have numerically almost the same value, but we keep them separated with different names for clarity. $U$ is not measured directly but is determined from the quantities $V_{\text {ave }}$ and $\alpha$ through a functional relationship $g$ :

$U=g\left(V_{\mathrm{ave}}, \alpha\right)=\frac{V_{\mathrm{ave}}}{k_{1} \cos \alpha}$.

$\alpha$ is also not measured directly but is determined from the quantities $V_{1}, V_{2}, V_{3}$ and $k_{\alpha}$ through a functional relationship $f$ :

$$
\begin{aligned}
\alpha & =f\left(V_{1}, V_{2}, V_{3}, k_{\alpha}\right) \\
& =\arctan \left(\frac{k_{1} \sqrt{3\left(V_{1}-V_{\mathrm{ave}}\right)^{2}+\left(V_{2}-V_{3}\right)^{2}}}{\sqrt{3} k_{2} V_{\mathrm{ave}}}\right) \\
& =\arctan \left(\frac{2}{k_{\alpha}} \frac{\sqrt{V_{1}^{2}+V_{2}^{2}+V_{3}^{2}-V_{1} V_{2}-V_{1} V_{3}-V_{2} V_{3}}}{V_{1}+V_{2}+V_{3}}\right)
\end{aligned}
$$

$V_{\text {ave }}$ is the average between $V_{1}, V_{2}, V_{3}$ calculated with the relationship $h$ :

$V_{\mathrm{ave}}=h\left(V_{1}, V_{2}, V_{3}\right)=\frac{1}{3}\left(V_{1}+V_{2}+V_{3}\right)$.

To calculate the uncertainty in $U$ we need first to calculate the uncertainty in $V_{\text {ave }}$ and $\alpha$.

The uncertainty in $V_{\text {ave }}$ is calculated applying the rule for combination of uncertainties in uncorrelated input quantities

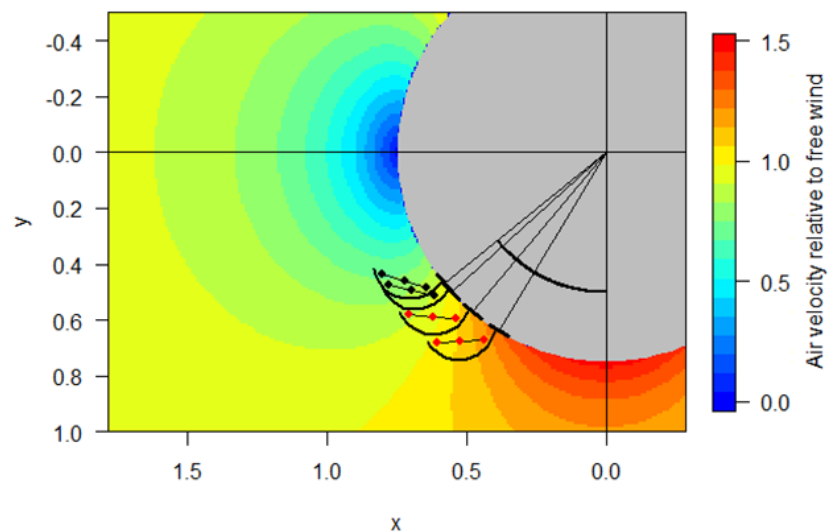

Figure 13. Simulation of the flow around the spinner, which was approximated to a sphere. The flow was calculated with the equations of the potential flow around a sphere. The sensor positions retrace the position of the sensors found in Fig. 12. The sensor paths with the red dots refer to the old mount $\left(31,40^{\circ}\right)$, while those with the black dots refer to the improved mounting $\left(48,51^{\circ}\right)$, where the sensors are more closely spaced.

(Eq. 10) to the function $h$ (Eq. 23), resulting in Eq. (24) assuming that $u_{1}=u_{2}=u_{3}$.

$u_{\mathrm{ave}}=\sqrt{\left(\frac{1}{3}\right)^{2} u_{1}^{2}+\left(\frac{1}{3}\right)^{2} u_{2}^{2}+\left(\frac{1}{3}\right)^{2} u_{3}^{2}}=\frac{u_{1}}{\sqrt{3}}$

The uncertainty in the inflow angle $\alpha$ can be calculated combining the uncertainty in $V_{1}, V_{2}, V_{3}$, and $k_{\alpha}$ applying Eq. (10) to the function $f$ (Eq. 22), resulting in Eq. (25):

$$
\begin{aligned}
u_{\alpha} & =\sqrt{\left(\frac{\partial f}{\partial V_{1}}\right)^{2} u_{1}^{2}+\left(\frac{\partial f}{\partial V_{2}}\right)^{2} u_{2}^{2}+\left(\frac{\partial f}{\partial V_{3}}\right)^{2} u_{3}^{2}+\left(\frac{\partial f}{\partial k_{\alpha}}\right)^{2} u_{k \alpha}^{2}} \\
& =\sqrt{3\left(\frac{\partial f}{\partial V_{1}}\right)^{2} u_{1}^{2}+\left(\frac{\partial f}{\partial k_{\alpha}}\right)^{2} u_{k \alpha}^{2} .}
\end{aligned}
$$

Given the complexity of the function $f$ (Eq. 22) the derivatives were computed numerically.

$V_{1}, V_{2}, V_{3}$ were calculated for a wind speed $U$ in a range 0-25 $\mathrm{m} \mathrm{s}^{-1}$ with Eqs. (27) to (29), for six arbitrary values of $\alpha$, and used to compute the partial derivatives of Eq. (25). The uncertainty in $k_{\alpha}$ was set to $u_{k \alpha}=0.1 \cdot k_{\alpha}$ as found by 


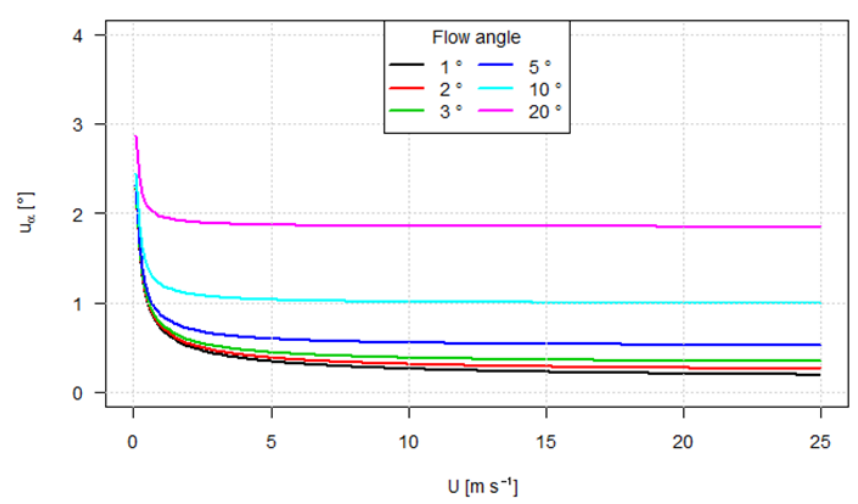

Figure 14. Uncertainty in the inflow angle $\alpha$.

Pedersen et al. (2015). In Fig. 14 one can see an uncertainty of about $1^{\circ}$ for a inflow angle of $10^{\circ}$.

The uncertainty in the vector wind speed $U$ can be calculated applying the method for combination of uncertainty in independent variables (GUM JCGM/WG1, 2008, Eq. 10) to the function $U=g\left(V_{\mathrm{ave}}, \alpha\right)$ (Eq. 21), resulting in Eq. (26):

$$
\begin{aligned}
u_{U} & =\sqrt{\left(\frac{\partial g}{\partial V_{\mathrm{ave}}}\right)^{2} u_{\mathrm{ave}}^{2}+\left(\frac{\partial g}{\partial \alpha}\right)^{2} u_{\alpha}^{2}} \\
& =\sqrt{\left(\frac{1}{k_{1} \cos \alpha}\right)^{2} u_{\mathrm{ave}}^{2}+\left(\frac{V_{\mathrm{ave}}}{k_{1}} \frac{\sin \alpha}{\sqrt{1+\alpha^{2}}}\right)^{2} u_{\alpha}^{2}} .
\end{aligned}
$$

The uncertainty in $U$ calculated for six arbitrary values of $\alpha$ with Eq. (26). $V_{\text {ave }}$ was calculated with Eq. (23) and $V_{1}, V_{2}$ and $V_{3}$ with Eqs. (27), (28) and (29). The results are shown in Fig. 15.

$$
\begin{aligned}
& V_{1}=U\left(k_{1} \cos (\alpha)-k_{2} \sin (\alpha) \cos (\theta)\right) \\
& V_{2}=U\left(k_{1} \cos (\alpha)-k_{2} \sin (\alpha) \cos \left(\theta-\frac{2 \pi}{3}\right)\right) \\
& V_{3}=U\left(k_{1} \cos (\alpha)-k_{2} \sin (\alpha) \cos \left(\theta-\frac{4 \pi}{3}\right)\right)
\end{aligned}
$$

As can be seen in Fig. 15, the uncertainty in $U$ is function of the flow angle $\alpha$. For inflow angles below $5^{\circ}$, Fig. 15 shows that the $u_{U}$ is basically only a function of $U$. A typical average inflow angle to a wind turbine is smaller than $5^{\circ}$, as presented in Pedersen et al. (2014). The uncertainty in the wind speed is typically a function of the wind speed only. In order to keep the calculation simple (especially in the calculation of power curve uncertainty), a simple model (Eq. 30, red crosses in Fig. 15) was fitted to the line corresponding to an inflow angle of $6^{\circ}$, which is unlikely to be exceeded on average during normal operation of most wind turbines in a range of wind speeds 4 to $20 \mathrm{~m} \mathrm{~s}^{-1}$.

$u_{U}=-0.005+\frac{\sqrt{U}}{80}$

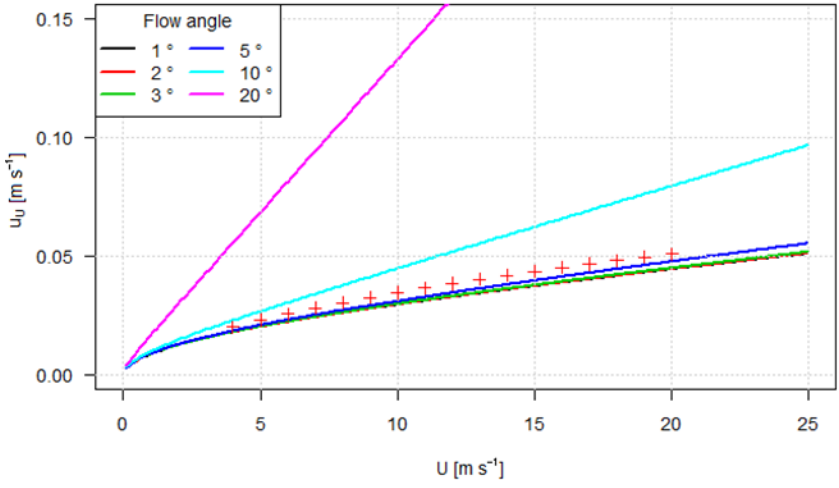

Figure 15. Uncertainty in wind speed $\left(u_{U}\right)$ as a function of wind speed $(U)$, for six possible values of inflow angle $\alpha$. Red crosses show the values of uncertainty as a function of wind speed for a common value of inflow angle of $6^{\circ}$.

Now that the uncertainty in the wind speed modulus $U$ is known, it is possible to calculate the uncertainty in its horizontal component $U_{\text {hor }}$. By combining the equations of the conversion algorithm (which can be found in Demurtas et al., 2016), $U_{\text {hor }}$ is expressed as

$$
\begin{aligned}
U_{\mathrm{hor}} & =i(U, \delta, \phi, \theta, \alpha) \\
& =\sqrt{(U \cos \alpha \cos \delta-U \sin \alpha \sin (\phi+\theta) \sin \delta)^{2}+(-U \sin \alpha \sin (\phi+\theta))^{2}} .
\end{aligned}
$$

The position of the flow stagnation point $\theta$ in Eq. (31) is a function of $V_{1}, V_{2}, V_{3}$. The rotor position $\phi$ is calculated based on the accelerometers located in each sonic sensor root. To be absolutely correct, one should apply the method for combination of uncertainty to Eq. (31). However, it is reasonable to assume that $U_{\text {hor }} \sim U$ due to the small inflow angle $\alpha$ and that $u_{U_{\text {hor }}} \sim u_{U}$ because the uncertainty in the wind turbine tilt angle $\delta$ and rotor position $\phi$ is likely to be smaller than the other uncertainty components. Moreover, the improved accuracy in the estimation of $u_{U_{\text {hor }}}$ would be removed by the simplification made with Eq. (30). Therefore, the uncertainty in the horizontal wind speed $U_{\text {hor }}$ is almost equal to the uncertainty in $U$ :

$u_{U_{\mathrm{hor}}}=u_{U}$.

\subsection{Uncertainty in spinner anemometer output}

The uncertainty $u_{\text {s.a. } 4}$ of the spinner anemometer wind speed measurements of wind turbine 4 (Eq. 33) is the combination of the uncertainty in the spinner anemometer output $\left(u_{U_{\text {hor }}}\right)$ with the uncertainty due to the discrepancies between different MEASNET wind tunnels $\left(U_{\mathrm{ME}}=1 \% / \sqrt{3}\right)$.

$u_{\text {s.a. } 4}=\sqrt{u_{U}^{2}+u_{\mathrm{ME}}^{2}}$ 


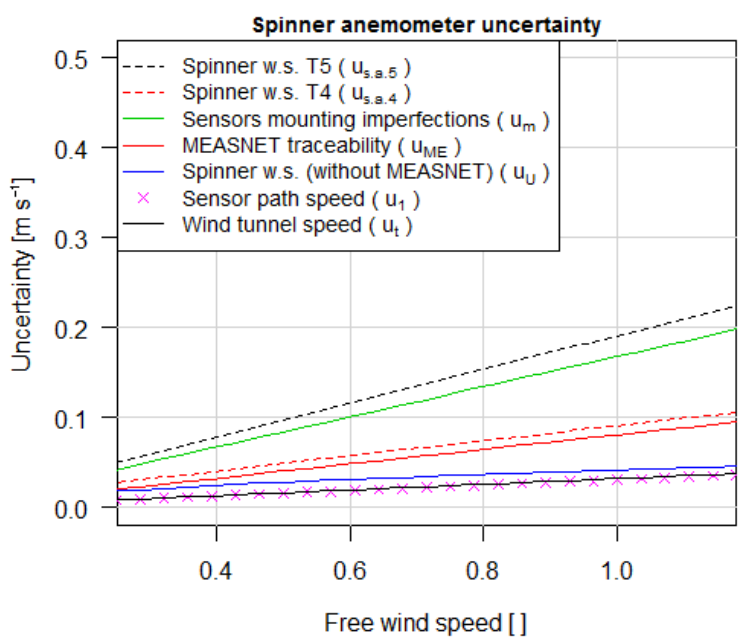

Figure 16. Overview of the size of the various uncertainty components and total uncertainty.

The uncertainty $u_{\text {s.a. }}$ on the measurements of the spinner anemometer on wind turbine 5 should also include the uncertainty due to mounting imperfections to account for the dissimilarity with the reference spinner anemometer on wind turbine 4:

$u_{\text {s.a. } 5}=\sqrt{u_{U}^{2}+u_{\mathrm{ME}}^{2}+u_{\mathrm{m}}^{2}}$.

Figure 16 shows the combination of each uncertainty term to the final uncertainty budgets. As can be seen in Fig. 16, the uncertainty in the sensor path speed (pink crosses) is very close to the wind tunnel speed (black line), due to the small contribution to the uncertainty coming from the uncertainty in the sensor path angle $\phi_{\mathrm{s}}$.

The spinner anemometer conversion algorithm combines the uncertainties in the spinner anemometer input quantities $\left(V_{1}, V_{2}, V_{3}, \phi\right)$, resulting in the blue line of Fig. 16. Once combined with the MEASNET traceability uncertainty (red line) we arrive to the dashed red line. Once including the uncertainty in the mounting imperfection (green line) we arrive at the black dashed line. Among the uncertainty components ascribable to the spinner anemometer, the one due to mounting inaccuracy of the sensors is the largest one. Note that the mounting imperfections are null for the reference spinner anemometer, in fact what matters is that the mounting position of the sonic sensors and the shape of the other spinner anemometers (on T5 in this case) are similar to the reference one (on T4 in this case). All the sonic sensors were calibrated in the same wind tunnel. The MEASNET uncertainty was added to $u_{U}$ instead of to $u_{1}, u_{2}$ and $u_{3}$ to avoid counting it three times.

\subsection{Uncertainty in met-mast measurements}

The uncertainty in the met-mast wind speed measurement (Eq. 35, Fig. 17) is (according to IEC61400-12-2, 2013) the

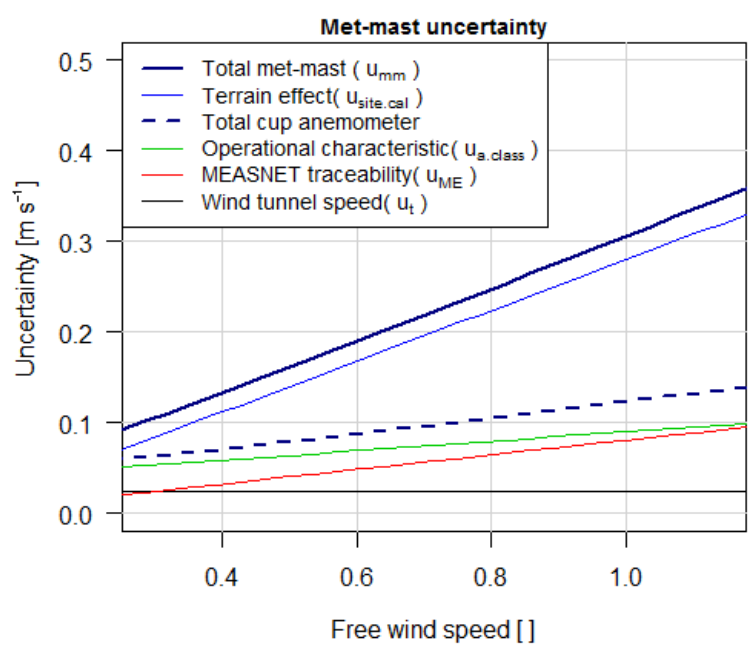

Figure 17. Overview of the size of the various uncertainty components and total uncertainty.

combination of the wind tunnel uncertainty $u_{\mathrm{t}}$, the MEASNET uncertainty to account the discrepancies between different wind tunnels $u_{\mathrm{ME}}$, the uncertainty due to the cup anemometer class $u_{\text {a.class }}$ (which takes into account the response of the cup anemometer to turbulence and flow inclination), and $u_{\text {s.cal. }}=2 \% V_{i}$ because there was no site calibration.

$u_{\mathrm{mm}}=\sqrt{u_{\mathrm{t}}^{2}+u_{\mathrm{ME}}^{2}+u_{\mathrm{a} . \text { class }}^{2}+u_{\mathrm{s} . \mathrm{cal}}^{2}}$

\subsection{Uncertainty in NTF}

The uncertainty in the NTF $\left(u_{\mathrm{NTF}}\right)$ is the combination of the various uncertainty components as

$u_{\mathrm{NTF}}=\sqrt{u_{\mathrm{mm}}^{2}+u_{\mathrm{s} . \mathrm{a} .4}^{2}+u_{\mathrm{M}}^{2}+s_{\mathrm{NTF}}^{2}}$,

where $u_{\mathrm{mm}}$ is the uncertainty in the measured free wind speed; $u_{\text {s.a. }}$ is the uncertainty in the spinner anemometer measurements; $u_{\mathrm{M}}$ is the uncertainty due to the NTF method, considered $2 \%$ of the wind speed due to seasonal variations $\left(u_{\mathrm{M}}=0.02 V_{i}\right)$ in the standard IEC61400-12-2; $s_{\mathrm{NTF}}$ is the statistical uncertainty in the captured dataset $\left(s_{\mathrm{NTF}}=\right.$ $\left.\frac{\sigma_{\mathrm{NTF}}}{\sqrt{N_{j}}} U_{\text {s.a. }}\right)$; and $\sigma_{\mathrm{NTF}}$ is dimensionless because it is the standard deviation of the ratio $U_{\text {free }} / U_{\text {s.a.4 }}$.

\subsection{Uncertainty in calculated free wind speed}

To measure the absolute power curve of a wind turbine the spinner anemometer output must be corrected to free wind speed by use of the nacelle transfer function (NTF). The uncertainty in the free wind speed is therefore a combination of 


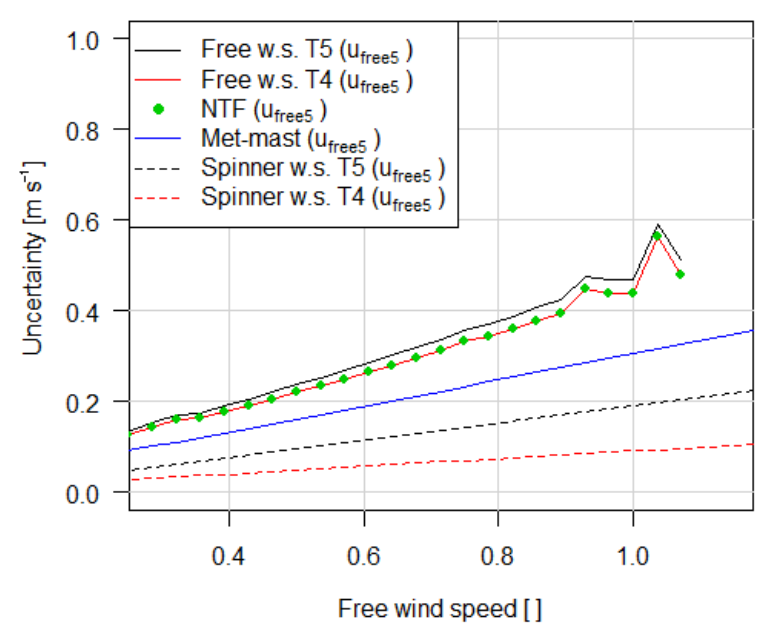

Figure 18. Uncertainty in wind speed. The met-mast wind speed includes $2 \%$ additional uncertainty due to lack of site calibration.

$u_{\text {s.a. }}$ with $u_{\mathrm{NTF}}$.

$u_{\text {free } 5}=\sqrt{u_{\text {s.a. } 5}^{2}+u_{\mathrm{NTF}}^{2}}$

For the case of the reference wind turbine (T4, used to measure the NTF) the uncertainty is calculated differently. $u_{\text {NTF }}$ already contains the uncertainty in the reference spinner anemometer (T4) and the uncertainty in the met-mast measurements. Therefore, the uncertainty in the free wind speed calculated with the NTF is just the uncertainty in the NTF (Eq. 38):

$u_{\text {free } 4}=u_{\mathrm{NTF}}$.

\section{Results of uncertainty analysis}

The mounting accuracy was investigated by overlaying six photos of the spinner taken from ground level during rotation, each showing the corresponding sensor when it is at the side of the spinner. The photos show deviations in the order of $\pm 2 \mathrm{~cm}$ between some of the sensors. It was expected that the mounting imperfections played a major role in the total uncertainty in the second spinner anemometer. However, the contribution of other uncertainty sources combined (the $1 / \sqrt{3} \%$ MEASNET traceability of wind tunnel calibrations for cup-anemometer on the met-mast and spinner anemometers sensors, the $2 \%$ for lack of site calibration) was much larger than the uncertainty due to the mounting of the sensors (which was $1.2 \%$ ).

As shown in Fig. 18, the uncertainty in the NTF is larger than the met-mast uncertainty, as expected. The met-mast uncertainty is larger than the spinner anemometer uncertainties (dashed lines) because of the $2 \%$ added due to missing site calibration, which does not apply to the spinner anemometer output (but applies to the NTF later to calculate the free wind speed). Wind turbine 5 has a larger uncertainty than the reference wind turbine, as expected, due to the mounting imperfections. Note that the distance between the two dashed lines is due to the mounting imperfections, but the impact of such imperfections is significantly reduced once the uncertainties in the spinner anemometer output are combined with the NTF uncertainty.

\section{Discussion}

The main goal of this study was to measure the power performance of a wind turbine using a spinner anemometer which was calibrated with the calibration determined on a "reference" spinner anemometer on an identical wind turbine. The calibration ( $k_{\alpha}$ and $k_{1}$ values) determined on the reference spinner anemometer can be moved to a second spinner anemometer estimating an additional uncertainty due to the mounting differences. This is only possible if the two spinners have the same outer shape. The mounting differences (and associated uncertainty) could be completely avoided if the positioning of the sonic sensors was exactly equal between the reference spinner and another spinner. This geometric perfection could be achieved with the collaboration of the manufacturer of the spinner by integrating the sensor mounting fittings in the mould so that all the spinners are fabricated identically.

The spinner anemometer was calibrated for wind speed measurement so that it reads the wind speed correctly in a condition of zero induction (stopped rotor, or operation at high wind speed). While this step is not essential because this correction can be included in the NTF, it is convenient to use the NTF to only correct the induction. When the spinner is calibrated for wind speed measurements, a change in the spinner anemometer configuration (for example, move the sensors to another point on the spinner) can be accounted for with a new $k_{1}$, and the NTF stays unvaried.

Application of the same NTF on another wind turbine is reasonable only if the wind turbine control strategy and the rotor are identical to the reference wind turbine. This requirement could, however, be removed if further research can demonstrate that the induction at the rotor center (which matters for the spinner anemometer) is unvaried for changing rotor diameter or control strategy.

The uncertainty due to discrepancies between MEASNET wind tunnels $\left(u_{\mathrm{ME}}=1 \% / \sqrt{3}\right)$ was combined with the uncertainty in the spinner anemometer output wind speed $\left(u_{U}\right)$, while a more correct approach would have been to include $u_{\mathrm{ME}}$ in the wind tunnel uncertainty $u_{\mathrm{t}}$. The first approach was used to keep the analysis of propagation of uncertainties (through the spinner anemometer conversion algorithm) free from contributions of constant terms (such as $u_{\mathrm{ME}}$ ), which would otherwise have masked the contribution attributable to the sole spinner anemometer conversion algorithm.

Adding the MEASNET uncertainty to the spinner anemometer output instead of to the input does not lead to a 
significant error in the total uncertainty, since the effect of the conversion algorithm on the uncertainties is small (as shown in Fig. 16 by the small distance between the pink crosses and the blue line, which is essentially due to the $10 \%$ uncertainty in $k_{\alpha}$ ).

If the spinner anemometer of the reference wind turbine (T4) is replaced, the uncertainty in the new spinner anemometer should be added to the NTF uncertainty $\left(u_{\text {free } 4}=\sqrt{u_{\text {NEWs.a.4 }}^{2}+u_{\mathrm{NTF}}^{2}}\right)$. If the dataset used to calculate NPC on T4 is different to the one used to measure the NTF, the type A uncertainty in the new dataset should be added to the NTF uncertainty $\left(u_{\text {free } 4}=\sqrt{u_{\mathrm{NTF}}^{2}+s_{\mathrm{NEW} . a .4}^{2}}\right)$.

Each sonic sensor (three for each spinner anemometer) should be calibrated in the wind tunnel and the results of the calibration set in the spinner anemometer conversion box (the procedure is explained in Demurtas, 2014). If a sensor fails and is replaced, the new wind tunnel calibration values should be set in the conversion box. If the sensors are not calibrated, a new (more difficult) calibration of $k_{1}$ should be made every time a sonic sensor is replaced.

The reference spinner anemometer should be calibrated in flat terrain. The calibration of the spinner anemometer for wind speed measurements and the measurement of the NTF can, in practice, be done with any free wind speed measurement device (met mast, nacelle lidar or ground based lidar). In complex terrain, a spinner anemometer should be assigned the calibration and NTF measured on an identical wind turbine as in a flat terrain. The free wind speed calculated applying the NTF to the spinner anemometer measurements in complex terrain might provide a free wind equivalent to the one of a flat site, with no need for site calibration. The measurement of the flow inclination angle by the spinner anemometer might in this case be very helpful as an additional parameter for correction or normalization of the power curve. The spinner anemometer might be well suited to measure in the wake of other wind turbines as turbulence and large flow inclination angles can be measured with reasonably good accuracy (Pedersen et al., 2014). However, it has to be kept in mind that the spinner anemometer is a point measurement, compared to the rotor swept area. If the rotor is partially operating in the wake of another wind turbine, the spinner anemometer measurement would not be representative of the average wind condition over the swept area.

\section{Conclusions}

The study investigated the methods to evaluate the power performance of two wind turbines using spinner anemometers.
The power curves of two adjacent wind turbines (T4, T5) were measured by means of a common traceable calibrated met mast and spinner anemometers on each wind turbine. All sonic sensors were calibrated in a traceable wind tunnel. T4 was the reference wind turbine. The reference spinner anemometer installed on T4 was calibrated with respect to angular and wind speed measurements to take into account the shape of the spinner and the mounting position of the sensors. The spinner anemometer on T5 was instead assigned the calibration constants of the reference spinner anemometer. Similarly, the NTF (nacelle transfer function) was measured on the reference wind turbine (T4) and applied to both wind turbines. The four power curves of the two wind turbines (two met-mast power curves and two spinner anemometer power curves) were compared in terms of AEP (annual energy production). The nacelle power curves compared very well with the met-mast power curves for a range of annual average wind speeds. The uncertainty in the spinner anemometer wind speed measurements was analyzed in detail, taking account of the propagation of the uncertainty through the spinner anemometer conversion algorithm. Some small approximations were made.

The sonic sensor mountings were verified with photos taken from the ground and a method for estimation of uncertainty related to mounting imperfections was proposed. The uncertainty in the free wind speed calculated with the NTF was mostly due to the uncertainty in MEASNET traceability and lack of site calibration. To a less significant extent, the uncertainty was due to the spinner anemometer sensor calibration and mounting imperfections.

In summary, under the condition that the mounting of the sonic sensors is very similar to the reference mounting, power performance measurements with the use of a spinner anemometer can be made within $0.38 \%$ difference in AEP for an annual average wind speed of $8 \mathrm{~m} \mathrm{~s}^{-1}$.

Data availability. The measurements used in this article are not available as they would disclose the absolute power performance of wind turbines 4 and 5 . 


\section{Appendix A: List of symbols}

$\alpha \quad$ Wind inflow angle relative to the shaft axis.

$\beta \quad$ Flow inclination.

$\delta \quad$ Wind turbine tilt angle.

$F_{1} \quad$ Calibration factor mainly related to wind speed calibration.

$F_{\alpha} \quad$ Calibration factor related to angle calibration.

$\gamma \quad$ Yaw misalignment.

$\phi \quad$ Rotor azimuth position (equal to zero when sonic sensor 1 is at top position, positive clockwise seen from the front of the wind turbine).

$\phi_{\mathrm{s}} \quad$ Angle of the sensor path with respect to the mounting plate.

$k_{1} \quad$ Calibration constant mainly related to wind speed calibration.

$k_{\alpha} \quad$ Calibration constant related to angle calibration.

$k_{2} \quad$ Calibration constant (equal to $k_{\alpha} \cdot k_{1}$ ).

$m \quad$ Slope coefficient of the wind tunnel calibration equation (generic).

$q \quad$ Offset of the wind tunnel calibration equation (generic).

$R \quad$ Radius of the sphere approximating the spinner.

$r \quad$ Radial coordinate in a polar coordinate system.

$\theta \quad$ Azimuth position of the flow stagnation point on the spinner measured clockwise from sensor 1.

$U \quad$ Wind speed vector modulus $\left(U=\sqrt{U_{\text {hor }}^{2}+w^{2}}\right)$.

$U_{\mathrm{s}} \quad$ Wind speed between 11 and $14 \mathrm{~m} \mathrm{~s}^{-1}$ used for normalization of wind speed measurements.

$U_{\text {hor }} \quad$ Horizontal wind speed (calibrated).

$U_{\text {hor,d }} \quad$ Horizontal wind speed (measured with default values $k_{1, \mathrm{~d}}$ and $k_{2, \mathrm{~d}}$ ).

$U_{\text {hor,d,c }} \quad$ Horizontal wind speed (calibrated with correct $k_{\alpha}$ but not correct $k_{1}$ ).

$U_{\mathrm{mm}} \quad$ Horizontal wind speed measured by the met mast at hub height.

$U_{\mathrm{mm}, n} \quad$ Horizontal wind speed measured by the met mast at hub height, corrected to standard air density.

$U_{\text {free4 }} \quad$ Free wind speed calculated with the nacelle transfer function from spinner anemometer measurements (wind turbine 4).

$U_{\text {free5 }} \quad$ Free wind speed calculated with the nacelle transfer function from spinner anemometer measurements (wind turbine 5).

$P_{\text {bin }} \quad$ Average power in wind speed bin.

$P_{\text {rated }} \quad$ Rated power.

$U_{0} \quad$ Free stream inlet wind speed used in the potential flow analysis.

$u_{1} \quad$ Uncertainty in $V_{1}$.

$u_{\mathrm{t}} \quad$ Uncertainty in $V_{\mathrm{t}}$.

$u_{\mathrm{m}} \quad$ Uncertainty in wind speed due to mounting imperfections.

$u_{\mathrm{M}} \quad$ Uncertainty due to the NTF method (seasonal variations equal to $0.02 V_{i}$ ).

$u_{\mathrm{ME}} \quad$ Uncertainty to account for the discrepancies between different MEASNET wind tunnels.

$u_{\mathrm{mm}} \quad$ Uncertainty in $U_{\mathrm{mm}}$.

$u_{\text {s.a.4 }} \quad$ Uncertainty in wind speed measurements of the spinner anemometer mounted on wind turbine 4.

$u_{\text {s.a.5 }} \quad$ Uncertainty in wind speed measurements of the spinner anemometer mounted on wind turbine 5.

$V_{1} \quad$ Wind speed in sensor path 1.

$V_{2} \quad$ Wind speed in sensor path 2 .

$V_{3} \quad$ Wind speed in sensor path 3 .

$V_{\text {ave }} \quad$ Average wind speed of sonic sensors.

$V_{\text {avg }} \quad$ Annual average wind speed used to calculate the wind speed probability distribution.

$V_{i} \quad$ Center wind speed of bin $i$.

$v_{\mathrm{r}} \quad$ Velocity component along radius in a polar coordinate system.

$v_{\mathrm{t}} \quad$ Velocity component perpendicular to radius in a polar coordinate system.

$V_{\mathrm{t}} \quad$ Wind tunnel air speed.

$w \quad$ Vertical wind component. 
Appendix B: List of abbreviations

$\mathrm{Cp} \quad$ Power coefficient of a wind turbine

IEC International Electrotechnical Commission

NPC Nacelle power curve

NTF Nacelle transfer function

PC Power curve

s.a. Spinner anemometer

SN Serial number

T4 Wind turbine 4

T5 Wind turbine 5 
Competing interests. The authors declare that they have no conflict of interest.

Acknowledgements. Romo Wind A/S is acknowledged for the good collaboration along the project and for the help in providing the spinner anemometer and power data of the Nørrekær Enge wind farm. Vattenfall A/S is acknowledged for providing access to the wind turbines used in the test and the help with installation of the met mast. This work was performed as part of the EUDP-2012-I project: iSpin (J.nr 64012-0107).

Edited by: F. Blaabjerg

Reviewed by: A. Cuerva and two anonymous referees

\section{References}

Demurtas, G.: Summary of the steps involved in the calibration of a spinner anemometer, Tech. Rep. I-0364, DTU Wind Energy, 2014.

Demurtas, G.: Power curve measurement with Spinner Anemometer according to IEC 61400-12-2, Tech. Rep. I-0440, DTU Wind Energy, 2015.

Demurtas, G. and Cornelis Janssen, N. G.: An innovative method to calibrate a spinner anemometer without the use of yaw position sensor, Wind Energ. Sci., 1, 143-152, doi:10.5194/wes-1-1432016, 2016.

Demurtas, G., Pedersen, T. F., and Zahle, F.: Calibration of a spinner anemometer for wind speed measurements, Wind Energy, 19, 2003-2021, doi:10.1002/we.1965, 2016.

Faith, A, F. and Morrison, A.: An Introduction to Fluid Mechanics, Cambridge University Press, 656-658, 2013.

Frandsen, S., Sørensen, N., Millense, R., Pedersen, T. F., and Antoniou, I.: The generics of wind turbine nacelle anemometry, EWEC Proceedings, Bruxelles, 2009.
IEC61400-12-1: Wind turbines - Part 12-1: Power performance measurements of electricity producing wind turbines, IEC, International Electrotechnical Commission, Switzerland, available at: https://webstore.iec.ch/publication/5429 (last access: 22 February 2017), 2005.

IEC61400-12-2: Wind turbines - Part 12-2: Power performance of electricity producing wind turbines based on nacelle anemometry, IEC, International Electrotechnical Commission, Switzerland, available at: https://webstore.iec.ch/publication/5430 (last access: 22 February 2017), 2013.

IECRE: OMC Clarification Sheet, IEC System for Certification to Standards Relating to Equipment for Use in Renewable Energy Applications, Switzerland, 2015.

JCGM/WG1: GUM - Evaluation of measurement data - Guide to the expression of uncertainty in measurements, Joint Committee for Guides in Meteorology of the BIPM, available at: http://www.bipm.org/utils/common/documents/jcgm/JCGM_ 100_2008_E.pdf (last access: 22 February 2017), 2008.

Krishna, V. B., Ormel, F., and Hansen, K. S.: Alternative approach for establishing the Nacelle Transfer Function, Wind Engineering, 40, 307-318, doi:10.1177/0309524X16647847, 2014.

Metek GmbH: Spinner Anemometer User Manual, Germany, 2009.

Pedersen, T. F.: Spinner anemometer - an innovative wind measurements concept, EWEC Milan, 2007.

Pedersen, T. F., Demurtas, G., Sommer, A., and Højstrup, J.: Measurement of rotor centre flow direction and turbulence in wind farm environment, Journal of Physics: Conference Series, 524, 012167, doi:10.1088/1742-6596/524/1/012167, 2014.

Pedersen, T. F., Demurtas, G., and Zahle, F.: Calibration of a spinner anemometer for yaw misalignment measurements, 18, 19331952, Wind Energy, Wiley, USA, 2015. 